\title{
Custo de Oportunidade: Conceitos e Contabilização
}

\section{Autores: Anísio Cândido Pereira Benedito Felipe de Souza Dauro Rodrigues Redaelli Joshua Onome Imoniana}

Doutorandos em Contabilidade e Controladoria no Departamento de Contabilidade e Atuaria da Faculdade de Economia e Administração da USP.

\section{Índice}

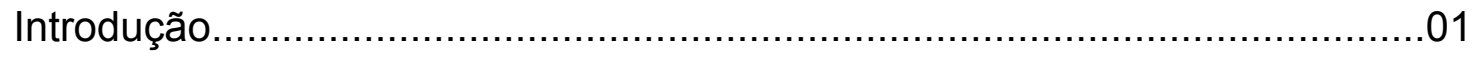

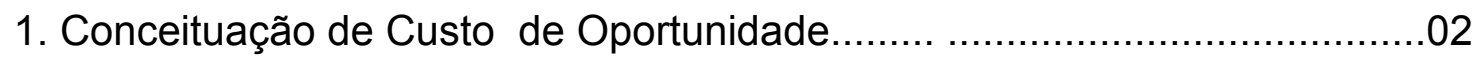

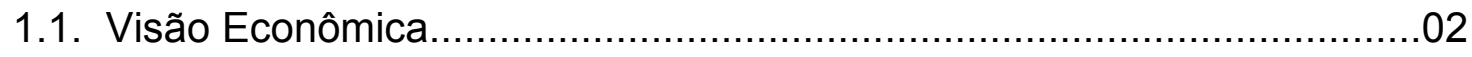

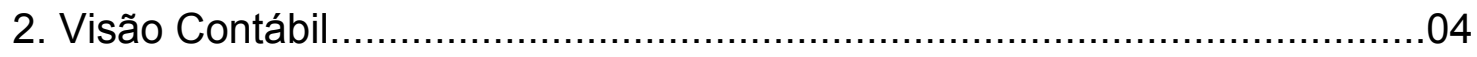

2.2. Juros sobre capital próprio como custo de oportunidade........................10

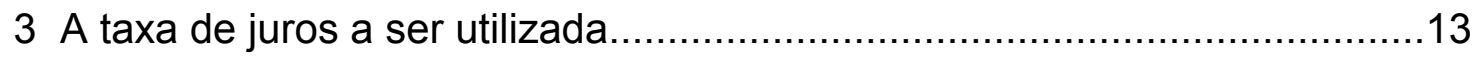

3.1 Contabilização dos juros sobre capital próprio..................................... 15

4. O Tratamento contábil proposto por Anthony.......................................16

4.1 O Tratamento Contábil proposto por Schlatier \& Schlatte.r....................18

4.2 Juros sobre o capital próprio na legislação Brasileira.............................. 23

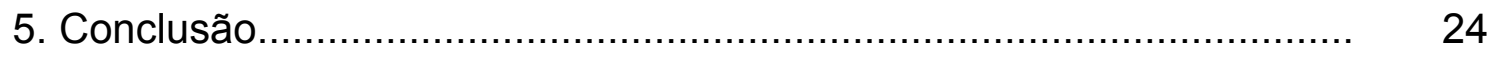

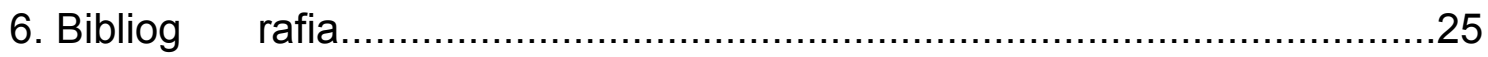




\section{Introdução}

Adaptação de trabalho de cunho acadêmico, este arquivo não é mais que um vol'oseau sobre a questão do curso de oportunidade, iniciando por sua origem na ciência econômica e, a partir daí, no como tem sido apresentado por alguns autores classificados como da Área contábil financeira. ““”.

É mostrado que o travestir o conceito do custo de oportunidade de "Juros sobre o capital próprio" foi a "saída emergencial" da contabilidade ao lhe ser feito o desafio para que incorporasse em seus registros o conceito oriundo da ciência irmã, tais as dificuldades que surgiram.

Assim, mesmo que uma solução definitiva não se tenha vislumbrado na literatura, ao constatar que tentativas existem são estímulos para que os contabilistas continuem abertos a mudanças e a todas as tentativas de aprimorar o poder informativo da contabilidade.

\section{Conceituação de Custo de Oportunidade}

\section{Visão Econômica}

A economia pode ser entendida como um estudo da escassez e dos fenômenos delas resultantes, de forma mais sofisticada, como o estudo da alocação de recursos escassos entre usos alternativos com vistas à satisfação das necessidades. 
Para construir uma teoria econômica, os economistas elaboram hipóteses amplas de forma que possam deduzir "Leis econômicas" também amplas.

Uma das hipóteses é a de que os seres humanos são racionais, querem sejam eles consumidores, quer sejam eles empresários: sabem o que fazem, sabem fazer o que sabem no momento em que devem faze-lo.

Outros sim são suficientemente perspicazes para não desperdiçar recursos que tenham em mãos, mesmo que tais recursos estejam, em determinado momento, materializados sob forma de moeda. Além disso, quando consumidores, os seres humanos buscam sempre a maior satisfação ; quando empresários, buscam entre outros objetivos, a maximização do lucro.

Para que aquela presumida perspicácia possa ser praticada, a Economia institucionaliza os "mercados onde as trocas ocorrem onde se presume a existência de estreito contato entre os que neles interagem e o pleno conhecimento, destes, sobre tudo o que está a ocorrer em tais mercados".

Os preços de bens e de serviços estão apresentados pela economia pela razão de troca entre eles em decorrência de sua escassez e de suas utilidades o que, em suma, viria a ser a expressão mais material do confronto entre o "desejo e possibilidade de ter" e o "desejo e possibilidade de ofertar"

Nem sempre nos textos econômicos a expressão "Custo de oportunidade" aparece de forma explicita. Por vezes os autores utilizam uma expressão sinônima: "Custos alternativos".

Segundo Burch \& Henry 1, foi Frederich Von Wieser quem deu origem à expressão "custo de oportunidade" para definir o valor de um fator de produção em qualquer uso que lhe fosse dado, sendo tal custo de oportunidade "a renda líquida gerada pelo fator (de produção) em seu melhor uso alternativo". O conceito de custos de oportunidade pressupõe alternativa viável e, portanto, existentes para o consumidor ou para o empresário. Pressupõe, também, uma decisão efetiva sendo tomada e que, o sendo, acarreta o sacrifício/abandono de outras (s) que não foi o (ram).

Assim, um consumidor $x$ ao optar por alocar parte de sua renda em um bem $\mathbf{A}$ qualquer, deixou de faze-lo em uma série de outros bens/serviços, que foram, portanto, alternativas abandonadas ou sacrificadas. Destas últimas a que maior satisfação lhe desse seria o custo de oportunidade de ter optado pelo bem $\mathbf{A}$.

A afirmação de que o "verdadeiro custo é o custo de oportunidade (o custo alternativo)" é encontrada em alguns textos.

Tal pode ser visto em MILLER 2 quando diz que: “....... custo em Economia significa apenas uma coisa - o custo de oportunidade".

O custo de oportunidade é definido como o valor do recurso no seu melhor uso alternativo. "Ou então em BILLAS,3" ao afirmar que "o custo dos fatores para uma 
empresa é igual aos valores destes mesmos fatores em seus melhores usos alternativos". Esta é a doutrina dos Custos alternativos ou de oportunidades e é a que o economista aceita, quando fala em custos de produção "“.".

LEFIWICH 4, após exemplificar sobre usos alternativos de um fator de produção, conclui que, "o custo de uma unidade de qualquer recurso usado por uma firma é o seu valor em melhor uso alternativo", a isso denominado de "principio do custo alternativo" ou "principio do custo de oportunidade, válido, segundo ele, para a sociedade como um todo, assim como para uma só firma".

O raciocínio econômico sobre o "custo de oportunidade" está intimamente ligado com o deslocamento dos fatores de produção de uma para outra atividade, o que não ocorre por simples acaso. O mercado que deseja o bem/serviço no qual estarão aqueles fatores, valida o preço de tal bem/serviço e, com isso, "autoriza" o mencionado deslocamento.

Do que esta até agora dito, concluí-se que é no mercado que a economia busca auxilio para valorar os fatores de produção lhes atribuindo, para tal, seus "custos de oportunidade". A conclusão conduz a indagação: "existe, então, uma listagem com os valores dos custos de oportunidade dos diversos fatores de produção?"

A resposta afirmativa viria o complemento de que "os valores nela constantes são os preços dos fatores tal como são praticados efetivamente no mercado" o mesmo que "os custos de oportunidade são os preços de mercado dos fatores de produção".

Esta simplificação didática - de que o valor do custo de oportunidade de um fator de produção é o valor que efetivamente foi arcado para ser possível consumi-lo repousa numa lógica ancorada nas hipóteses macroeconômicas que permitem raciocinar em termos de intervalos infinitamente pequenos entre o "valor do custo arcado" e "o valor do seu custo de oportunidade", devido à quantidade intensa de negociações que se supõe ocorrer no mercado, responsáveis por sucessivos deslocamentos de posições: se um valor é custo de oportunidade nesta negociação é porque foi valor de um custo praticado "há pouco" e o valor de um custo praticado "agora" será o custo de oportunidade da "próxima" negociação.

Do que exposto, cabem as mesmas perguntas feitas por J.R. GOULD 5 sobre"que tudo isto ensina, ou auxilia, o administrador no seu dia a dia? "A ligação conceito econômico de custo de oportunidade com situações especificas das empresas é valida e, como se verá, não foi esquecida

\section{visão contábil Financeira}

Saindo do campo da economia e adentrando na literatura pertinente a atividades especificas de empresa 
isoladamente observadas no contexto econômico, o "custo de oportunidade" aparece com assiduidade nos textos de administração financeira e nos de contabilidade gerencial, bem como nos de contabilidade de custos que não se limitam a analisa-la sob a ótica de custos para fins de "balanços e resultados".

Mas, mesmo em alguns desses últimos aparece o custo de oportunidade "disfarçando" sob o manto de "juros sobre o capital próprio", via de regra a ser abandonada a questão dos gastos gerais de fabricação.

A titulo de ilustração são apresentadas algumas conceituações observada em alguns dos autores. LEONE 6 diz que "custo de oportunidade é o valor do benefício que se deixa de ganhar quando, no processo decisório se toma um caminho em detrimento de outro." Para GRAY \& JOHNSTON 7, um custo de oportunidade é o lucro que poderia ter sido conseguido se um conjunto de recursos tivesse sido aplicado num certo uso alternativo ", enquanto que para MARTINS 8 representa o custo de oportunidade o quanto à empresa sacrificou em termos de remuneração por ter aplicado seus recursos numa alternativa ao invés de outra."

Os três conceitos se calcaram em duas alternativas possíveis de serem tomadas, mas impossíveis de serem levadas a cabo concomitantemente. Alem disso, o custo de oportunidade de uma alternativa é medido por alguma característica da alternativa abandonada. Para LEONE essa característica é o "beneficio que se deixa de ganhar" para GRAY \& JOHNSTON é o "Lucro que se poderia ter conseguido", enquanto que para MARTIN é o "quanto à empresa sacrificou em termos de remuneração".

Os exemplos (teóricos) citados por dois desses autores condizem com suas conceituações. LEONE invoca o que denomina de "exemplos tradicionais da literatura técnica" (1) o do rendimento obtido pelo aluguel que a firma poderia obter se assim procedesse com um terreno disponível quando fosse essa cotejada com a alternativa de usar tal terreno para suas atividades fabris; e (2) os salários que os donos poderiam estar obtendo se trabalhassem para outros patrões ao invés de para si próprios.

Já MARTINS busca algo num nível mais estratégico: recursos usados para fabricar sorvetes cotejados com os mesmos recursos aplicados em outro investimento ao alcance do empresário.

Depreende-se daí que existem (pelo menos em teoria) "Custos de oportunidade" associados a vários níveis da estrutura decisorial de uma empresa, desde aqueles que poderiam ser responsáveis pela continuidade (ou não) da própria empresa, até os que se envolvem em atividades mais rotineiras e menos abrangentes, como "parar as máquinas 'já' para Ihes dar manutenção e deixa-las trabalhar por mais 200 horas" ou, ainda, dar na própria empresa o polimento de uma peça já torneada por ela ou mandar polir fora ."'“. 
Se um custo de oportunidade é o custo resultante de uma alternativa a qual se tenha renunciado, tal como conceituam BACKER \& JACOBSEN 9, talvez fosse melhor explicar que, em existindo duas alternativas igualmente possíveis mas não concomitantemente realizáveis, o custo de oportunidade de uma delas é a renuncia do (a) outra.(?)

O "ponto de interrogação" tem sua razão de ser pois cabem, naquele lugar da sentença, tanto as palavras "beneficio/, como" receita ",como" custo ", como" resultado "(lucro/prejuízo), ou" valor ", ou" recebimento liquido de caixa ", ou.... Observa-se que não há na literatura um consenso sobre este" trecho "da definição razão, talvez, para a alegada dificuldade e operacionalizar o" custo de oportunidade "(por parte dos estudantes) como verificado no artigo de LEININGER 10, o qual, por esse motivo, propôs duas definições operacionais para o"Custo de oportunidade" a partir da constatação de que as situações praticas em que eles se aplica poderiam ser bipartidas em situações de custo e em situações de lucro. Numa situação em que as decisões se relacionam tão somente com custos, é aceitável a preocupação didática da separação feita. Todavia, é difícil dizer o mesmo das situações de lucros, uma vez que o lucro (resultado)envolve sempre dois componentes redituais simétricos - receitas e despesas- ambos podendo ser diferentes em cada uma das alternativas. A não ser que assuma, como no exemplo de LEININGER, que é imutável um de tais componentes.

Outro aspecto a considerar nas conceituações de custo de oportunidade é que em algumas - como as já citadas, não há uma qualificação, relativamente uma alternativa abandonada, quando duas alternativas existem, e só duas, o custo de oportunidade da primeira é buscado em alguma característica da segunda (lucro, custo, valor, etc.) e o custo de oportunidade da segunda é (lucro, custo, valor) e o custo de oportunidade da segunda é "algo" (lucro, custo, valor) da primeira.

Verificando como um exemplo, onde o custo de oportunidade é estabelecido como o lucro da alternativa abandonada, suponha-se duas delas, ambas aceitáveis mas não possíveis de serem realizadas ao mesmo tempo:

\section{Alternativa $A$}

$\$$

Receitas

Custos

Lucro.
Alternativa B

$\$$

120

35 
O custo de oportunidade da alternativa A seria de $\$ 35$ e o custo de oportunidade da alternativa B seria de $\$ 20$.

Foi apenas a aplicação das conceituações (Lembrando que a característica para mensurar o custo de oportunidade era o lucro o atributo escolhido). Nada mais.

Quando mais de duas alternativas existem, como a seguir:

\section{Alternativas}

$\begin{array}{llll}A & B & C & D \\ \$ & \$ & \$ & \$\end{array}$

Receitas

$120100 \quad 110$

Custos

Lucro

$35 \quad 20 \quad 12$

As conceituações vistam conduziram a resposta de que existem três custos de oportunidade para qualquer uma das quatro alternativas existentes.

Observou-se, então, assim que em outros conceitos de custo de oportunidade os autores incluíram na qualificação para o atributo escolhido como caracterizador do custo de oportunidade, uma qualificação do tipo "melhor", "pior", etc.É o caso de SIZER 11, ao dizer que custo de oportunidade concerne a melhor alternativa da qual se desistiu, observe-se que, para SIZER, a própria alternativo é o atributo, o que de certa forma, torna o conceito compacto e deixa o cargo do usuário caracterizar o que lhe é conveniente.

Outro conceito em moldes similares é o apresentado por MORSE \& ROTH 12: O custo de oportunidade de uso de um recurso em um modo específico é o recebimento liquido de caixa esperado que poderia ser obtido se o recurso fosse usado na outra ação alternativa mais desejável (tradução livre).

Por fim, GLAUTIER \& UNDERDOWN 13 entendem que custo de oportunidade pode ser medido como o valor da próxima melhor alternativa abandonada, ou 0 recebimento liquido de caixa permitido como resultado de preferir uma alternativa ao invés da melhor seguinte (tradução livre).

Usando o lucro liquido como caracterizador (como atributo) de uma alternativa, a conceituação de SIZER aplicada ao exemplo das alternativas A, B, C e D, levaria ao seguinte raciocínio, o custo de oportunidade da alternativa B é \$ 35 . Mas o custo de oportunidade da alternativa $C$ também é de $\$ 35$, também o sendo da alternativa $\mathrm{D}$. Isso, pois, qualquer que tenha sido a escolha ( $B$, ou $C$ ou $D)$, a alternativa $A$ é, ainda a melhor. Todavia se a alternativa $A$ fosse escolhida, seu 
custo de oportunidade seria de \$20: o lucro da alternativa B, a melhor que foi rejeitada.

Os exemplos da utilização do conceito de custo de oportunidade são freqüentes nos livros consultados apesar de, em alguns deles, não ser alertado ao leitor que, no dia-a-dia da vida de uma empresa não existe, para uma possível decisão a ser tomada, um organismo gerador do custo de oportunidade de tal decisão, de modo que o empresário/administrador possa decidir por ela ou não. Em outras palavras, supondo que há uma decisão possível que conduza a um resultado positivo de\$ 50. Se houvesse aquele organismo e se ele informasse que a decisão pretendida do empresário tem um custo de oportunidade de $\$ 70$, provavelmente ele não a tomaria pois estaria deixando de ganhar (lucrar) \$70 para lucrar apenas $\$ 50$.

Houvesse essa facilidade, por certo boa parte das dores de cabeça dos empresários estaria resolvida. Mas não há!

Então, como o custo de oportunidade oriundo da economia (é apregoado pelos economistas como o verdadeiro custo) auxilia o empresário/Administrador?

Porque críticas ao não uso do custo de oportunidade pela Contabilidade se ele não está disponível?

O motivo do desentendimento, crê-se, esta na falta do entendimento entre as partes. O provável conselho que emana dos que apregoam o uso do custo de oportunidade no dia-a-dia das empresas é o de praticamente para toda a ação a ser tomada existem alternativas possíveis que devem ser consideradas adequadamente antes da decisão ser tomada, e assim procedendo se estaria provavelmente tomando uma melhor decisão e, por detrás desse comportamento, usando o conceito de custo de oportunidade.

Observa-se, pois, que o conceito de custo de oportunidade tanto em economia, como em Contabilidade e em Finanças tem como fundamento à questão da escolha entre alternativas de utilização de recursos, todavia, ele - custo de oportunidade - só aparece claramente após as alternativas terem sido elencadas e mensuradas.

Um exemplo de que antes afirmado pode ser observado numa situação, em que uma empresa BC se defronta com as alternativas de utilizar determinado local que possui como ponto de venda ou arrenda-lo para terceiros, que lhe oferecem $\$$ 20.000 de aluguel mensal. Ora, se usar não pode arrendar, e vice versa.

O custo de oportunidade de continuar usando é de \$20.000(a alternativa abandonada), mas isso nada diz aos administradores da empresa ABC. Ou seja, esta única informação não lhes permite decidir. 
Todavia, se tabulado o resultado liquido propiciado pelo ponto de vendas em questão e esse Ford de $\$ 30.000$ por mês, a empresa pode concluir pela decisão de mantê-lo em uso, como sendo a mais vantajosa entre as duas alternativas alencadas na suposição de existirem outras variáveis.

Na Literatura sobre custos é comum ser encontrado, com maior ou menor profundidade, algo sobre preço de transferência, técnica que visa auxiliar a administração no que pertine a mensurar o desempenho econômico de cada centro de responsabilidade (há quem utilize centro de custo), e também, e também como um dos fatores balizadores para motivação de encarregados e fixação de gratificações destes. As técnicas de fixação dos preços de transferência são diversas e isso pode ser observado na obra de HENKE Jr.\& EDWARDS 14 sendo uma das "não baseadas em preços de mercado", a que se utiliza do "custo de oportunidade".

\section{Juros sobre Capital próprio como Custo de Oportunidade}

Apesar de economistas e contadores concordarem com o fato das despesas serem mensurações monetárias de recursos consumidos por uma empresa no processo de obter suas receitas, no campo pratica um economista raciocina em termos de que o custo é o valor do "custo de oportunidade" reconhecendo explicitamente o problema de escolha entre alternativas, em quanto que 0 contador ("tradicional") raciocina em termos de alternativas tomadas e, em isso ocorrendo, não considera as alternativas, que nos diversos momentos no processo decisório, existam para serem tomadas.

O gerente, que no dia-a-dia enfrenta problemas de escolha entre alternativas muito provavelmente se vale do conceito de custo de oportunidade, mesmo sem saber que, ao Alencar alternativas convenientemente preparadas em função de cada ação para escolher melhor delas, esta se valendo daquele conceito.

Surgem, então, movimentos no sentido de que a Contabilidade se aproxima da economia para dar tratamento aos custos de oportunidade e, com isso, auxiliar a administração.

As barreiras que surgem são varias, sendo uma delas a da objetividade, tão arraigada na Contabilidade, porque muito do que desta é gerado se utiliza para relatórios externos que geralmente devem ser aditados para que sejam "aceitos" como validos. Outrossim, a Contabilidade tradicional se vale do custo histórico como base de valor enquanto que em economia, o conceito do custo de oportunidade está preso a valores de hoje, mais especificamente a valores de realização, no momento em que aceito que a moeda é o elo de ligação para possibilitar um uso alternativo entre o recurso possuído e o próximo melhor recurso que deveria ser possuído. Observa-se, pois, quão grande o passo a ser dado pela contabilidade para utilizar o conceito de custo de oportunidade com a sua concepção economicamente pura. 
Outros obstáculos surgem da tentativa da Contabilidade aplicar o conceito do custo de oportunidade nos moldes econômicos. BURCH \& HENRY 15, ao R e b a t e r e m o artigo de MC ERA 16, vão a origem do conceito, tal como lhe deu FREDERICK VON WIESER, para mostrar que ele foi concebido em nível de cada recurso com que lida a economia. Os citados autores exemplificam $\mathrm{p}$ a $\mathrm{r}$ a o caso de máquinas e de mão-de-obra para alcançarem o nível de aceitar que o conceito poderia ser aplicado, também para um conjunto de recursos.

O importante da argumentação de BUCH \& HENRY é que, há vários níveis de custos de oportunidade em decorrência dos níveis decisórios existentes nas empresas e que, se alguns deles envolve o uso alternativo de específicos recursos (fatores de produção), outros envolvem conjuntos de ativos e, até mesmo, a empresa como um todo.

A operacionalização, pela contabilidade, da teoria do custo de oportunidade ao nível do item do Ativo, se não impossível no plano teórico, é de difícil alcançamento no plano prático e, por certo cairia na discussão do assunto "custo versus benefícios". Não significa que se deva desprezar a possibilidade de sua aplicação com o rigor exigido em casos específicos e não rotineiros.

Raciocinando que, "qualquer pessoa concorda que é melhor estar aproximadamente certo do que inteiramente errado", é que ANTHONY 17, apresenta situação conciliatória entre o levar em conta e o não levar em conta, pela contabilidade, a questão do custo de oportunidade.

A solução conciliatória de ANTHONY se baseia nas seguintes considerações. Os ativos têm sua origem nos capitais próprios o nos de terceiros, fato que a contabilidade já aceita. Passaria então a encarar o valor global daqueles "capitais" como se fossem os ativos e, tal como estes, poderiam receber usos alternativos que não o de serem aplicados nos ativos (atuais) tendo, pois, um custo de oportunidade.

Os recursos de terceiros, possuem seus custos de oportunidade que, serem assumidos serem seus custos contábeis, já são reconhecidos naturalmente, o que já é prática habitual inclusive para fins de relatórios externos.

Todavia, a Contabilidade (tradicional) não considera qualquer custo para os capitais próprios. Tratar-se-ia, portanto, de considerar tal custo e, ao assim procedendo, passar a utilizar o conceito de custo de oportunidade também para os capitais próprios.

A proposta de ANTHONY representa a "ponte" entre a conceituação de custo de oportunidade no campo da macro-economia e sua aplicação em nível de empresa individual, uma forma de superar as dificuldades, se observada a questão em nível de cada elemento individual do Ativo, com o uso de um valor que o substitui (os capitais próprios e os terceiros).

Caderno de Estudos nº 02, São Paulo, FIPECAFI - Abril/1990 
Provavelmente muitos autores que abordam a questão não chegam ás suas origens macroeconômicas para não dificultar o entendimento do assunto entre seus leitores. Por isso mostram o custo de oportunidade como o "juro de capital próprio", como se todo estivesse sempre materializado num só ativo: a moeda em caixa. O que, de forma alguma, significa que esteja desmerecendo a inclusão dos custos de oportunidade em suas obras. Deve-se ter presente, no entanto, a simplificação feita e que não substitui o conceito original de FREDERICH VON WIESER, se pudesse ser facilmente utilizado.

Um exemplo que permite visualizar a inclusão do juro dos capitais próprios, supondo-os valendo $\$ 20.000$ e que, se não fossem aplicados nos ativos da empresa $X$ poderiam ser aplicados dois outros conjuntos alternativos de ativos, propiciaram retornos líquidos de $15 \%$ e de $12 \%$. Admitindo-se de forma compacta a seguinte estrutura de resultado apurado de forma tradicional.

Receitas 10.000

Despesas de Custos....... 6.000

Lucro Tradicional.................4.000

A empresa $X$ poderia desejar saber qual o seu verdadeiro resultado se assumisse que deveria ter, dentre seus custos, mais um: o resultado liquido da melhor alternativa abandonada por ter aplicado os $\$ 20.000$ na empresa X. Procederia assim:

Receitas ..........................10.000

Despesas de Custos........ . 6.000

Lucro Tradicional.................4.000

Retorno Liquido

dos Capitais próprios.............3.000

Lucro econômico.................1.000

Com o rendimento de $12 \%$ não é o melhor (dentre as alternativas abandonadas por ter aplicado os $\$ 20.000$ nos existentes ativos da empresa X), não foi levado em conta.

Se, todavia, ao elenco das três alternativas fosse agregada mais uma também viável e na qual os $\$ 20.000$ pudessem ser aplicados pela empresa X com um rendimento liquido de $26 \%$ o lucro econômico dela passaria a ser negativo em $\$ 1.200$, ou seja, ( $\$ 4.000-26 \%$ de $\$ 20.000)$ indicando que ela poderia ter dado um melhor destino aos $\$ 20.000$, sem tê-los aplicado nos atuais ativos. 
Do que até aqui exposto observa-se pois, que os juros sobre o capital próprio são apenas umas das facetas do assunto custo de oportunidade o qual pode ser utilizado em outras situações do dia-a-dia das empresas, isso para ficar no campo do mundo dos negócios.

\subsection{A Taxa de Juros a Ser Utilizada}

Trata-se, agora, de algumas palavras sobre a taxa a ser utilizada. Antes de qualquer coisa convém relembrar que se trata de juros sobre capital próprio "de uma empresa" e as taxas alternativas devem dizer respeito às alternativas que "a empresa" teria para o seu capital próprio. Logo, Alencar dentro as taxas alternativas, taxas que os proprietários pensam poder obter com aqueles recursos financeiros e cometer um erro: o de confundir a empresa com elas.

O alerta abriria campo para uma série de discussões muito amplas. Por exemplo, a taxa alternativa (a ser usada no calculo) a rentabilidade que empresas do mesmo ramo estão obtendo, mais situadas em locais com características sócio econômicas diferentes? É taxa alternativa que poderia ser obtida se os recursos hoje aplicados (suponha-se no fabrico de parafusos) fossem utilizados para o fabrico de doces e pães?

De imediato observa-se que a questão - já bastante simplificada para ser operacionalizada - ainda apresenta pelo menos esse ponto polemico.

Os autores consultados que preconizam a utilização dos juros sobre o capital próprio não "fecham a questão" em torno da taxa a ser utilizada.

SCHLATLER \& SCHLATLER 18, por exemplo, falam que "a taxa usualmente selecionada é aquela pela qual o dinheiro poderia ser emprestado na região com uma razoável segurança do principal” (tradução livre pág. 706).

HANSEN 19 posiciona-se no sentido de que o mais habitual é usar um tipo de juros que mais ou menos corresponda ao que, em geral, se deve pagar no mercado para obter o dinheiro.

Após isso, e chegando a cogitar em algum tipo de variável de juros (associado aos diversos tipos de ativos) acaba por sugerir uma só taxa que, por motivos de consistência, deve-se ser usada durante todo o exercício social.

A sugestão de ANTHONY 20 para a taxa de juros sobre o capital próprios, parte dos percentuais de participação dos capitais (próprios e de terceiros) sobre o total das origens de recursos, os quais utiliza como "pesos". Como a taxa de juros dos capitais de terceiros é conhecida pela empresa, sobre ela é aplicado o "peso" correspondente encontrando o que denomina de "custo ponderado dos capitais de terceiros". 
Ele supõe conhecida (ou pelo menos disponível para as empresas) a taxa média do custo dos capitais totais (próprios e de terceiros) e dela subtrai o "custo ponderado dos capitais próprios". Por fim, dividindo este último por seu respectivo "peso" chega na taxa de juros dos capitais próprios da empresa específica.

Com a taxa de juros dos capitais de terceiros utilizado é fiscalmente dedutível, a obtida (dos capitais próprios)

Também o é no plano teórico, o que exigirá cuidado especial na etapa de contabilização.

Qualquer das abordagens apresentadas sobre a taxa de juros do capital próprio não esgotam a questão. Estase ciente de que há estreita relação entre a taxa e cada empresa em particular e com o modo de cada uma destas encara a questão do risco e da incerteza, diante das alternativas que possuem para investir seus recursos próprios.

\section{Contabilização dos Juros Sobre Capital Próprio}

Nesta seção é abordada a questão de como a Contabilidade pode tratamento aos juros sobre o capital próprio.

Para facilidade de entendimento será ela - a Contabilidade - didaticamente dividida em duas partes, a saber:

- A Contabilidade Financeira (ou externa) cujos relatórios acabam sendo usados para fins de divulgação externa, via de regra auditados; e

- A Contabilidade Gerencial (ou interna) cujos frutos servem para finalidades administrativas várias, podendo, ou não manter vinculo de ligação (maior ou menor) com a Contabilidade Financeira.

A Contabilidade Gerencial pode ser aqui assumida como a que tem dentro de si o encargo de tratar da questão custos e esta última pode, apenas por simplificação, ser subdividida em duas: "custos para avaliação de estoques" e "custos para finalidades gerenciais".

O termo "contabilizar" será reservado, aqui, apenas para os casos em que trata de Contabilidade Financeira. Na outra, a Gerencial se usarão expressões tais como "será contemplado", "será levado em conta" "será considerado". 
Dos autores consultados que tratam do assunto, todos sem exceção, se posicionam favoravelmente a que os juros sobre o capital próprio possam ser levados em consideração pela Contabilidade Gerencial.

Dentro dela, as formas de tratamento divergem conforme o autor, SCHLATLER \& SCHLATLER 2, por exemplo, concluem que "se o objetivo primordial da contabilidade de custos é de melhor auxiliar o controle sobre os custos, e não apenas ser meio auxiliar de avaliar estoques, a inclusão dos juros pode ser altamente desejável" (tradução livre).

Eles não excluem a possibilidade de que, considerados nos estoques pela Contabilidade Gerencial

, sejam os juros sobre o capital próprio contabilizado pela Contabilidade Financeira. Todavia, no mecanismo sugerido para esta última ocorre uma compensação dos "juros" de modo que não afetam o resultado final que seria obtido sem sua inclusão.

O autor citado, juntamente com HANSEN 22 e com DUCH 23 aparece para se situar na corrente dos autores germânicos preocupados com a alocação de todos os custos aos produtos. A eles se junta ANTHONY que deixa essa posição explicitada no seu artigo.

Contrapondo-se a esta corrente, mas defendendo a consideração dos juros sobre o capital próprio nos custos para tomada de decisão, encontra-se MARTINS 24, no afirmar que o custo de oportunidade, pode ser um custo fixo, se alocado aos produtos, pode conduzir a situações enganosas em função dos critérios arbitrários que inevitavelmente existem se tentando o rateio de todos os custos fixos aos produtos. Segundo ele, já que o custo de oportunidade (usado como sinônimo de juros sobre o capital próprio) não deve receber registro na Contabilidade Financeira, deve ser pela Gerencial, usado de forma que auxilie na tomada de decisões (preconiza o "custeio variável") ao invés de ser usado com a preocupação de ser alocados aos produtos.

Dos autores consultados, apenas MARTINS é claramente contrário a Contabilização dos juros sobre o capital próprio.

ANTHONY, ao contrario, é adepto a que tal ocorra em sua plenitude e com todos os seus efeitos. Já HANSEN, DUCH e SCHLATLER \& SCHLATLER, apesar de concordarem com a contabilização, operacionalizam através de mecanismos tais que os juros acabam por não afetar a Contabilidade Financeira e seus resultados finais tradicionais.

A seguir são mostrados os tratamentos para os juros sobre o capital próprios encontrados em ENTHONY e em SCHLATLER \& SCHLATLER. 


\subsection{O Tratamento Contábil Proposto por ANTHONY}

ANTHONY expõe de um modo sucinto a forma de contabilizar os juros sobre o capital próprio, a qual se constitui no seguinte.

Numa conta, aqui denominada de "Juros Reais e Imputados" (o autor a denominou de "Interest Pool"), São debitados duas espécies de juros. Uma delas são os juros sobre os capitais de terceiros (os "juros reais"). Todavia, como esses últimos são despesas fiscalmente dedutíveis (não o são os primeiros) acabariam gerando um ganho relativo de impostos de renda. Isto motiva o autor a proposta de expurgar dos juros sobre os capitais de terceiros tal "beneficio fiscal relativo" e essa parcela expurgada acabaria numa conta de despesa que denominou "Ajustamento Fiscal".

A partir de então, o saldo devedor da conta "Juros Reais e Imputados" possui ambos os juros, considerados fiscalmente indedutiveis apenas para a finalidade alocativa pretendida pelo autor. Ou seja, a provisão para o imposto de renda que utiliza continua a mesma.

Quem propicia a compensação no resultado é a conta "Ajustamento fiscal" .

Logo a seguir o saldo devedor (já depurado) na conta juros reais e imputados, se torna nulo com vários lançamentos a credito, cujos débitos serão feitos nos ativos nos quais os juros devem ser alocados. Um deles recai nos estoques de produtos (o autor não explicita, mas pode ser entendido que se trata de uma apropriação do tipo Custeio por Absorção).

Quando vendidos tais estoques, o "custo de vendas" terá dentro de si uma parcela de juros apropriados. Os remanescentes no ativo terão, também, uma parcela de juros que thes compete.

O outro crédito feito na Conta Juros Reais e Imputados tem como contra partida os imobilizados sendo que a parcela não alocável a aos ativos acaba por voltar ao resultado como despesa do exercício.

Observa-se então, que pela proposta de ANTHONY nem todo o saldo devedor da Conta de Jurfos Reais Imputados transforma-se em despesa do exercício qual seja: as parcelas que ficaram "presas" em ativos, "superavaliando-os" se comparada à proposta com os procedimentos da Contabilidade Tradicional.

As contra-partidas credoras dos débitos iniciais da conta Juros Reais e Imputados são agora explicitadas. Os créditos relativos aos juros dos capitais de terceiros ("reais") são os tradicionalmente feitos: contas de Passivo ou diretamente em Disponibilidades. 
O crédito relativo aos juros sobre os capitais próprios ("Imputados") se faz, no entender do autor, numa conta especial do Patrimônio Liquido ou, até mesmo, na própria conta Lucros Acumulados. Esse é, na realidade, o "valor mais" que adentrou na Contabilidade tradicional e que, segundo ANTHONY, é inevitável pela aceitação do Método, mas que, todavia, dali em diante permanecerá oscilante apenas em função dos níveis dos ativos (estoques imobilizados). Acrescente-se, pois, não o fez o autor, também em função da taxa que for adotada.

Ressalta-se, finalmente, que "a mais" acrescido ao Patrimônio Liquido acaba compensando pela redução do lucro e, no que faltar, pelo aumento de valor dos ativos. Só que, tal aumento não é fruto apenas dos juros sobre capital próprio mas de ambos: capitais próprios e de terceiros.

Feita a proposta, ANTHONI destaca as razões para que devesse ser implementada. A empresa, entidade distinta dos sócios, deve ser observada na sua capacidade de geração de resultados sendo que estes, agora, passariam a ter uma conotação mais próxima da que a Economia Ihes dá, quer por considerar o custo total do capital, quer por ser este custo mais próximo do custo de oportunidade. Outrossim, no processo continuo de geração de riquezas todos os fatores de produção estariam considerados nos ativos (observa-se que o atual tratamento dos juros dos capitais de terceiros é o de considera-los despesas do período, sem qualquer relação com o fluxo de ativos).

Ao lado dessas vantagens, o autor aponta que o resultado obtido seria mais limpo, no sentido de que "mais capaz no auxilio das decisões dos investidores e que os resultados publicados seriam mais próximos dos resultados usados internamente para fins gerenciais".

Sem dúvida, a proposta do autor da um tratamento dos juros sobre o capital próprio, juntamente com os juros com os capitais de terceiros, de forma tal, a buscar a avaliação dos ativos da forma mais próxima do conceito econômico, por neles imputar a carga de ambos os juros.

Todavia, valeu-se ele dos custos históricos (pouco importa se corrigidos ou não) o que, de forma alguma, encurta a distância entre o procedimento contábil e a realidade econômica que estaria, a cada instante avaliando tais ativos pelo preço de realização.

\subsection{Tratamento Contábil Proposto por SCHLATLER \& SCHLATLER}

O Tratamento proposto por SCHLATLER \& SCHLATLER, será mostrado na forma como o apresentado no original com a supressão, apenas, do exemplo intermediário dado pelos autores, o que em nada prejudica o desenvolvimento. 
Os exemplos imputam os juros sobre o capital próprio, calculado apenas sobre os ativos fixos. Os autores reconhecem ser isto uma simplificação pois, se o argumento de tais juros fazem parte do custo (por se um "custo") poderiam se imputados a todos os ativos. No entanto, segundo eles, devido às dificuldades reais

Geralmente são computados apenas nos ativos fixos e só em situações não usuais é que são imputados aos demais ativos.

Os exemplos de SCHLATLER \& SCHLATLER usam tão somente os juros, calculados na base de uma taxa de $6 \%$ ao ano, tratados como custos fixos decorrentes da aplicação daquela taxa nos ativos fixos do prédio (de valor \$100.000) no qual se localizam três departamentos: dois produtivos (A e B) e um de serviço de energia. Os ativos próprios (máquinas e equipamentos) desses departamentos são $\$ 1.00 .000$ (o de energial), e $\$ 200.000$ (A) e $\$ 80.000$ (B). A área total utilizada por eles é, na ordem em que enunciados, de $20 \%$, e $30 \%$. A Distribuição da energia gerada é de $60 \%$ para A, e $40 \%$ para B. É suposto inexistirem produtos em elaboração e produtos prontos no inicio do período. A planilha de distribuição dos juros anuais é mostrada a seguir:

\section{PLANILHA DE DISTRIBUIÇÃO DOS CUSTOS FIXOS}

\section{$-B-$}

PREDIO Energia -A-

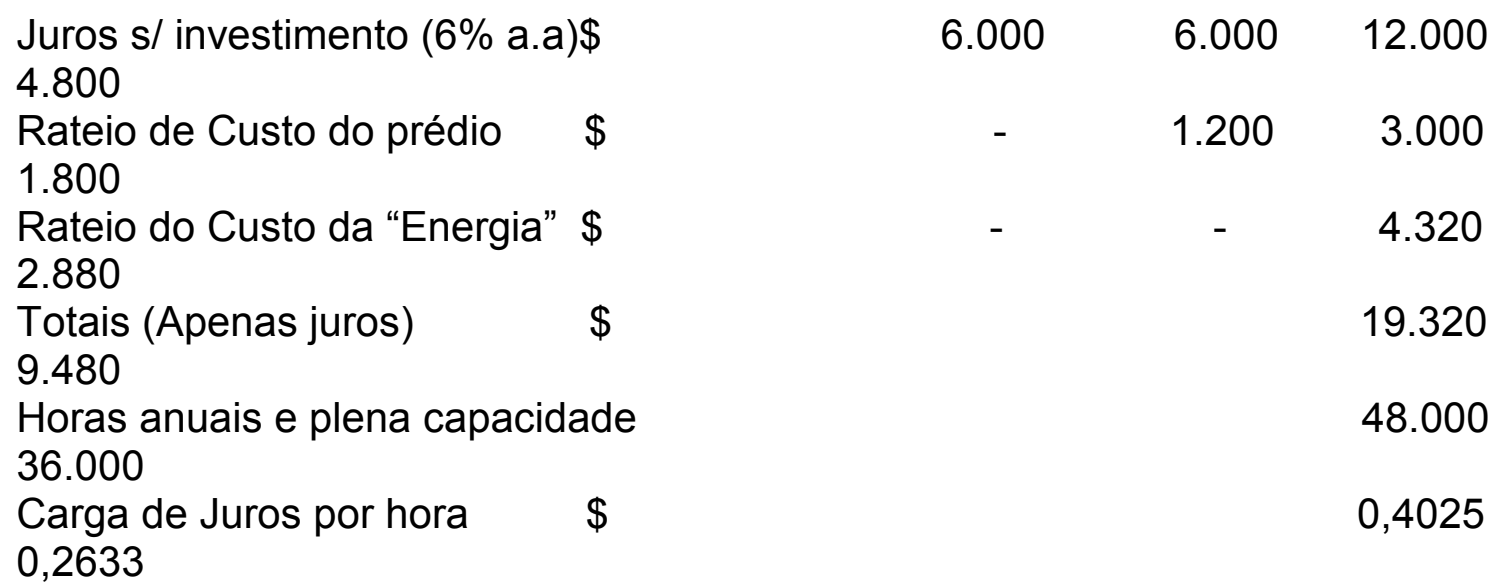


Com esses dados básicos nascem os dois exemplos, aqui denominados de caso 1 e caso 2, cada um dos quais com seu conjunto de lançamento mostrado em "razonetes" próprio.

\section{Caso 1}

No final do primeiro mês de atividade nada restam de produtos em elaboração ou de produtos prontos em estoque. Os lançamentos são brevemente comentados, já que "amarrados" com letras:
A) Conduz a contas próprias os juros mensais (fixos) calculados sobre os investimentos (a conta creditada é uma espécie de conta auxiliar);
B) Transfere os juros do "Edifício" para os três setores
C) Transfere os juros do departamento de serviços para os dois departamentos produtivos (não restam juros para trás);
D) Suposto atingida a plena capacidade, todos os juros são Transferidos para a produção em Andamento (isso não ocorrendo, os valores creditados seriam menores que os débitos já acumulados);
E) Reconhece que todos os juros ficaram incorporados nos produtos acabados;
F) Reconhece que todos os juros contidos nos estoques se transformaram em resultados;
G) Apura o resultado transferindo o saldo do custo dos Produtos Vendidos para a conta Apuração do Resultado;
H) Transferem o saldo da Conta Juros Imputados ao custo para a conta Apuração do Resultado;
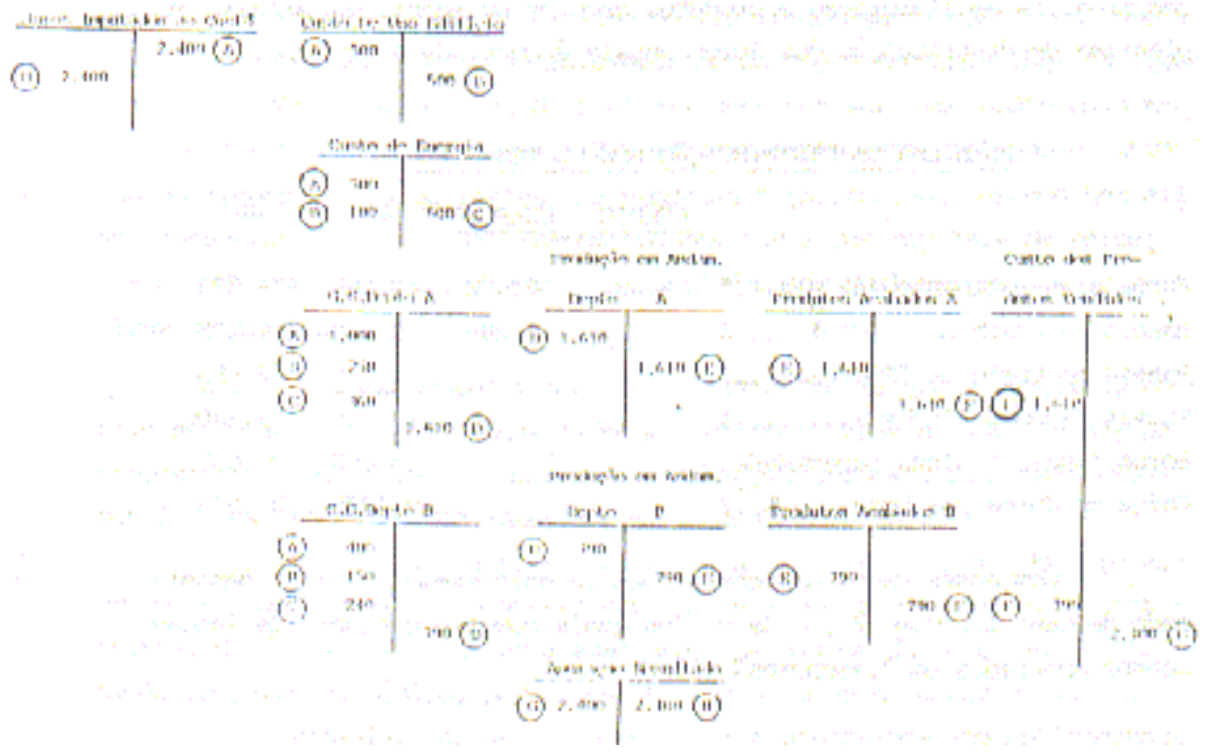

Caderno de Estudos no 02, São Paulo, FIPECAFI - Abril/1990 


\section{Caso 2}

Esse caso supõe que as atividades dos departamentos A e B foram de 3.600 horas e 2.700 horas respectivamente. É suposto que os produtos concluídos no mês consumiram 2.400 horas (o produto $A$ ) e 1.800 horas (o produto $B$ ).

Quanto às vendas, os produtos $A$ vendidos contêm 2.000 horas enquanto que os produtos $\mathrm{B}$ vendidos, 1.500 horas.

Inexistiam produtos em elaboração e produtos prontos no início do mês.

\section{Os lançamentos são os seguintes:}

A) Idêntico ao caso 1;

B) Idêntico ao caso 1;

C) Idêntico ao caso 1;

D) Transfere para as respectivas produções em andamento, os juros proporcionais às horas de atividades dos departamentos, ou seja $\$ 1.449$ (3.600 horas $\times \$ 0,4025)$ e $\$ 711(2.700 \times \$ 0,2633)$. Após este lançamento, resta saldo devedor nas contas que foram creditadas;

E) Como restaram produtos em elaboração, são transferidos para as contas de Produtos Acabados os valores relativos às horas consumidas nos produtos prontos;

F) Transfere para o custo dos produtos vendidos os valores correspondentes às horas contidas nos produtos vendidos; 
G) Transfere da conta Custo de Produtos vendidos para a conta de apuração do Resultado;

H) Transfere do saldo da conta juros imputados ao custo valor correspondente aos juros não absorvidos na produção bem como o contido no custo das vendas. Após este lançamento, o saldo da conta juros imputados ao custo é o valor dos juros contidos nos estoques (em elaboração e prontos);

I) Propicia o saldamento das contas de gastos gerais (A e B pelos valores não absorvidos);

J) Transfere o saldo da conta juros imputados para uma conta retificativa do Ativo, o que propicia que os juros existentes nos estoques (de produtos em elaboração e prontos) não influenciem o valor dos estoques, supervalorizando-os, casos comparados com os da Contabilidade tradicional.

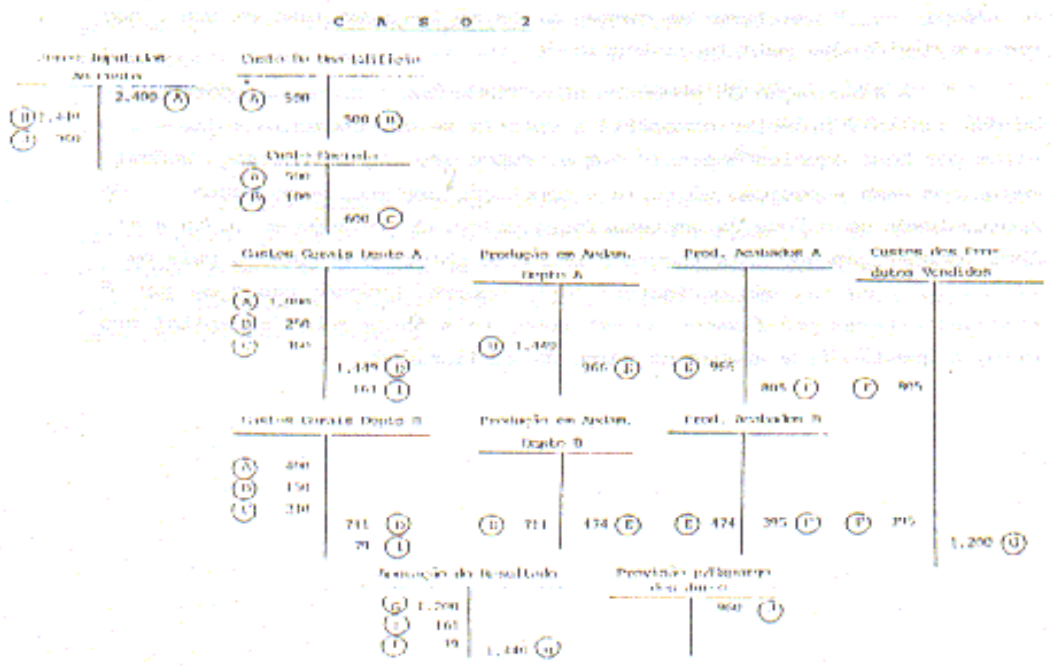

A solução proposta por SCHLATLER \& SCHLATLER, parece ter tentado satisfazer, tanto aos partidários da inclusão dos juros sobre o capital próprio, como os não partidários, na medida em que os "juros" incluídos nos custos acabam por não afetar os resultados finais.

Não houve, pois, por parte desses autores, o mesmo arrojo observado em ANTHONY que assumiu os estoques "carregados" pelos juros (inexistiria, na ótica de ANTONY, a provisão para expurgo dos juros estoques) com seu correspondente reflexo no Patrocínio Liquido. 


\subsection{Juros Sobre o Capital Próprio na Legislação Brasileira}

A lei das sociedades anônimas prevê a possibilidade de companhia calcular, registrar e pagar juros aos acionistas na fase pré-operacional do investimento. A legislação fiscal admite que tais juros sejam considerados dedutíveis.

Nada impede que a forma do calculo de tais juros sejam previstos no Estatuto Social e NADA IMPEDE que sejam calculados tomando por base os recursos. Via de regra monetária, alcançada pelos acionistas à sociedade. É uma forma de compensar os sócios numa fase em que não recebem dividendos pela inexistência de lucros.

A associação do procedimento citado com o custo de oportunidade dos capitais próprios começaria a existir se os mencionados juros tiverem por base àqueles capitais o que, supõe-se, seja a regra. Todavia, mesmo com essa suposição só teria a conotação pretendida do custo de oportunidade se o ônus da empresa fosse calculado levando em conta a melhor remuneração que tais recursos poderiam obter se aplicados pela empresa. Como tal obrigatoriamente ocorre, havendo casos em que é possível estarem pré-fixados no Estatuto, tais juros sobre o capital próprio, a questão fica apenas no campo da similaridade.

Se no campo da economia o conceito de custo de oportunidade está sintonizado com as hipóteses desta ciência, a tentativa de seu uso no dia-a-dia das empresas pode causar mais dúvidas do que auxílios, salvo se for adaptado convenientemente a situações especificas, quando então se torna um poderoso auxiliar nos tomadores de decisão, principalmente por exigir o elencamento de "todas" as possíveis alternativas antes da decisão.

A incorporação pela Contabilidade, daquele conceito, na forma original que the deu a economia, esbarra em dificuldades, a primeira sendo a necessidades de valores registrados passarem a ser os de "saída", mas especificamente, os de "realização". A este entrave esta intimamente ligado o da aversão ao subjetivismo, ao qual reagem os contabilistas, pelo menos quando os relatórios que geram, visa divulgação externa. Há também a dificuldade de operacionalização do conceito em nível de itens específicos de ativos, ou mesmo a conjuntos destes e a questão do "Custo versus benefício" seria freqüentemente invocada.

As propostas apresentadas neste trabalho mostram que o registro dos juros sobre o capital próprio é uma simplificação do assunto de contemplar, na Contabilidade, o custo de oportunidade, começando por substituir os ativos pelos capitais que Ihes deram origem e aceitando que os já registrados "juros sobre capitais de terceiros" refletem parte daquele custo de oportunidade, o que é discutível. A 
inclusão dos juros sobre o capital próprio na Contabilidade, mesmo que desconsiderada a questão dos riscos das alternativas (como foi neste trabalho), ainda encontra percalços no "modus operandi" de eleger a taxa a ser utilizada.

Apesar desses fatores adversos, o reconhecimento dos "juros sobre o capital próprio" deve ser estimulado no processo de tomada de decisões, bem como incentivadas todas as tentativas que visem operacionalizar que sejam eles formalmente incorporadas nos registros contábeis, tais como as apresentadas neste trabalho. 
B I B L I O G A F I A

1. ANTHONY, Robert N. "Accounting for the cost of equity". Harvard Business Review. November-december, 1973. p. 88-102.

2. BACKER, Morton \& JACOBSEN, L.E. Contabilidade de Custos: 'Ima Abordagem Gerencial. São Paulo. McGraw-Hill. 2a.edição 1984.

3. BENKE Jr., L. Ralph \& EDWARDS, James D. Transfer Pricing: Techni ques and'l ses. New York. National Association of Accountants. 1980.

4. BILAS, Richard A. Teoria Microeconômica. Rio de Janeiro. Forense Universitária. 1973.

5. BURCH, E.E. \& HENRY, W.R. "Opportunity and Incremental Cost; Attempt to Define in Systems Terms: A Corment". The Accounting Review. January. 1974, p. 118-123.

6. DuCH, Antonio G. Manual Basico de Calculo de Costos y Contabilidad Industrial. Barcelona. Marcombo S.A. 1957.

7. FLORENTINO, Américo M. Custos: Princípios, Cálculo e Contabiliza ção. Rio de Janeiro. Editora da Fundação Getûlio Vargas. 8a. eđição. 1983.

8. GLAUTIER, M.W.E. \& UNDERDOWN, B. Accounting: Theory and Practice. London. Pitman Publishing Limited. $3^{\text {th }}$ edition. 1986.

9. GOULD, J.R. The Economist's Cost Concept and Bussiness Problems. Studies in Accounting Theory. Richard D. Irwin. Inc.Illinois. 1962. pp. 218-235.

10. GRAY, Jack \& JOHNSTON, Kenneth S. Contabilidade e Administração. São Paulo. McGraw-Hill, 1977.

11. GUERREIRO, R. \& SPERANDIO, O. Contabilização do Custo de Oportunidade. São Paulo. FEA/USP. Trabalho apresentado na discipli na Teoria da Avaliação Patrimonial. 1985.

12. HANSEN, Palle. Contabilidad Interna de la Industria. Madrid. Aguilar. 1957.

13. IUdICIBUS, Sérgio de. Contabilidade Gerencial. São Paulo. Atlas. 3a. edição. 1980.

14. LEFTWICH, Richard $\mathrm{H}$. Introduction to Nicroeconomics. New York. Holt, Rinehart and Winston, Inc. 1970.

15. LEININGER, Wayne E. "Opportunity Costs: Some Definitions and Examples". The Accounting Review. Janeiro. 1977. pp.248-251.

16. LEONE, George S.G. Custos: Planejamento, Implantação e Controle. São Paulo. Atlas. 1982. 
17. MARTINS, Eliseu. Contabilidade de Custos. São Paulo. Atlas. 3a. edição. 1987.

18. Mc KENNA, Joseph P. A Handbook of Price Theory. New York. Holt. Rinehart and Winston, Inc. 1972.

19. MC RAE, T.W. "Opportunity and Incremental cost: An Attempt to Define in Systems Terms". The Accounting Review. April , 1970, pp. 315-321.

20. MILLER, Roger Leroy. Microeconomia: teoria, questões \& aplicações. Rio de Janeiro. MoGraw-Hill do Brasil. 1981.

21. MORSE, Wayne J. \& ROTH, Harold P. Cost Accounting: Processing, Evaluation and't sing Cost Data. Addison Wesley Publishing. $3^{\text {th }}$ edition, 1986. p. 36 .

22. SHCLATTER, C.F. \& SCHLATTER, W.J. Cost Accounting. New York. John Wiley \& Sons. Inc. $2^{\text {nd }}$ edition, 1957.

23. SIZER, John. Noções Bäsicas de Contabilidade Gerencial. São Pau lo. Saraiva. la. edição. 1974. 